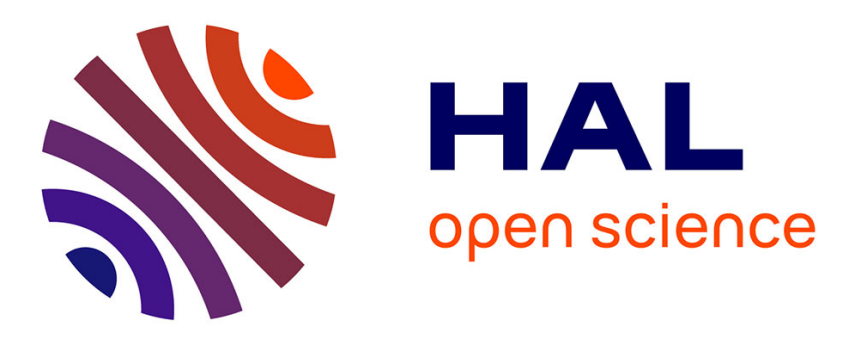

\title{
Integrating Asterisk with InRule to Detect Suspicious Calls
}

\author{
Ahmad Hammoud, Daniel Bourget
}

\section{To cite this version:}

Ahmad Hammoud, Daniel Bourget. Integrating Asterisk with InRule to Detect Suspicious Calls. AICT 2010 : sixth Advanced International Conference on Telecommunications, May 2010, Barcelone, Espagne. pp.153 - 160, 10.1109/AICT.2010.93 . hal-02276436

\section{HAL Id: hal-02276436 https://hal.science/hal-02276436}

Submitted on 2 Sep 2019

HAL is a multi-disciplinary open access archive for the deposit and dissemination of scientific research documents, whether they are published or not. The documents may come from teaching and research institutions in France or abroad, or from public or private research centers.
L'archive ouverte pluridisciplinaire HAL, est destinée au dépôt et à la diffusion de documents scientifiques de niveau recherche, publiés ou non, émanant des établissements d'enseignement et de recherche français ou étrangers, des laboratoires publics ou privés. 


\section{Integrating Asterisk with InRule to Detect Suspicious Calls}

\author{
Ahmad Hammoud \\ Dépt. Informatique \\ Telecom Bretagne \\ Bretagne, France \\ e-mail: a.hammoud@scopeexperts.com
}

\author{
Daniel Bourget \\ Dépt. Informatique \\ Telecom Bretagne \\ Bretagne, France \\ e-mail: daniel.bourget@telecom-bretagne.eu
}

\begin{abstract}
Monitoring telecommunications systems is of a crucial importance. Nowadays, PBX software packages can be configured to allow the storage of Call Detail Records in a database. There is a permanent need to analyze those records and allow business owners to detect PBX misuse from inside and outside the company. The word "misuse" covers an employee making too many personal phone calls, a salesman making fewer phone calls than expected, a client making an excessive number of phone calls, and other suspicious calls. A data-mining package or any other analytical tool would not be as efficient because it would report what happened when it is too late to take action. In this article, we integrate Asterisk with a rule-based engine called InRule. Asterisk will consult InRule whenever a call is about to be made and thus take appropriate actions.
\end{abstract} CDR.

Keywords-PBX; Asterisk; Rule-based engine; InRule;

\section{INTRODUCTION}

The PBX (Private Branch eXchange) might be misused by employees making personal calls, long local calls, many international calls, or mobile calls to clients that can be reached through land lines. Business owners need to analyze the CDRs (Call Detail Records) and act accordingly. In traditional scenarios, the dial plan developer might decide to let the CDR analysis logic be hard coded inside the dial plan. He might do so to make sure appropriate measures are immediately taken when a fraudulous activity is detected. Consequently, the following problems might arise: (i) Every time the system administrator wants to implement a new rule, update an established one, or change an action, the dial plan needs to be changed and reloaded. This might introduce bugs to the dial plan. It will also require system restart, which means that all current phone calls would be terminated. (ii) The dial plan is complicated since it includes both logic to lead the caller and logic to detect misuse. (iii) The checking process inside the dial plan is slow because it is synchronous. This will exhaust the CPU (Central Processing Unit) of Asterisk's server. (iv) Business owners do not have the technical know-how to implement / update rules by themselves.

We will start by describing our proposed method. Then, we move to related work in this area. Next, we list the advantages of using RBE and present the imposed challenges. Then, we describe the flow of events. Sample rules and actions are presented in Section VII. After that, Products configuration is described. At the end, we exhibit the results, the limitations and our conclusion.

\section{THE PROPOSED SOLUTION}

In this article, we describe how to integrate Asterisk with an RBE (rule-based engine) called InRule. Other RBEs could have been selected. Some are opensource packages. Asterisk will receive the call, instruct the RBE to perform the required analysis, receive its decision, and take actions such as sending an email, making a phone call, recording the call, or ending it.

This approach will allow the following benefits:

- There will be no need to update the dial plan. Instead, RBE rules will be updated

- The dial plan is simple and straightforward. It just calls the RBE, which in turn will decide what to do with the current call.

- The checking process can be asynchronous which means that the call will be normally handled by Asterisk even if the RBE did not yet return an action.

- The CPU of Asterisk server will not be consumed by the analytical logic. Instead, the RBE server will handle the analysis.

- Individuals lacking technical expertise will be able to develop their own rules.

- Rules are documented and can be used with any other PBX.

- Analysis is made by an engine designed and optimized to enforce rules.

\section{RELATED WORK}

One might think data mining techniques and tools may be an alternative to what we present in this article. In reality, they do not because there is a need for an engine that will receive the call request and send the reply immediately. This package should test the request against a long list of rules, and if any of the rules is violated, the package should send a reply specifying the action to be taken. Thus, an RBE package is necessary; $\mathrm{RBE}$ is not just an analysis tool that will receive a copy of 
the Master.csv file and give a report of the patterns and violations. In a real time response, the RBE package will propose taking one or many of the following measures on the current call: ending the call, recording it, forwarding it, sending an email, or calling the administrator. The $\mathrm{RBE}$ will be connected to the database that Asterisk uses to store the CDRs. This engine will be consulted by Asterisk each time a call is about to be made. Asterisk will receive the reply from the $\mathrm{RBE}$ and do appropriate actions.

Some researchers tackled the same problem but with a simpler architecture, a proprietary $\mathrm{PBX}$, and a different scope [1]. Our architecture makes use of a Web Service that can be called either synchronously or asynchronously depending on the performance results. This web service is a separate layer that can be replaced by any other web service dealing with a different RBE. Our architecture includes five servers: Asterisk + Web Application + Web Service + RBE + RDBMS. That way, load is better balanced and consequently better performance is gained.

\section{ADVANTAGES OF USING RBE}

The following are some advantages of using RBE:

- The individuals who will design, test, and verify the rules are not necessarily developers. They would not be required to have extensive knowledge about dial plans.

- A separate server will be used for the analysis.

- The RBE has GUI (Graphical User Interface). It also has tools necessary to test and verify the rules.

- When updates are introduced, dial plan is not affected.

- Business owners can at any time enable and disable a rule through the use of the RBE tools. Each rule has 2 properties: start date and end date. A rule might be used only for a period of time.

- When using an RBE, one tells "What to do" instead of telling "How to do it". This is called Declarative programming.

- When rules are documented, knowledge is centralized.

- There will be better logging for decisions and the reasons why they have been made.

- $\quad$ Since rules change quite often, the RBE provides the required agility.

\section{CHALLENGES}

Asterisk stores valuable information about all calls passing through the server. However, Asterisk might 'miss' some calls. In such a case, Asterisk will not be able to $\log$ them. Suppose one allowed the SIP (Session Initiation Protocol) devices to 'reinvite'; this means that the devices will not need Asterisk once it has finished setting up the call. If CDRs are of crucial importance, IP devices should not be allowed to 'reinvite'. The option "canreinvite" is used to tell the server to never issue a reinvite to the client [3]. This feature can be turned off by disabling 'reinvites' (canreinvite=no) in the sip configuration file (sip.conf). With notransfer=yes, similar functionality can be controlled in iax.conf.

Many questions might arise when it is time to plan for the integration of Asterisk and InRule, such as:

- How will Asterisk - running under Linux - call the RBE - running under Windows?

- How will the RBE check the CDRs which are stored in a Linux file instead of a database?

- How will the RBE reply to Asterisk?

- How will Asterisk notify system administrators?

The answer to all of the above questions is to simply use http request. A special web application can be developed to handle all communication between Asterisk, $\mathrm{RBE}$, and the CDR database.

\section{FLOW OF EVENTS}

The events will occur in the following order:

- Asterisk receives a call and sends an HTTP request using the CURL function. CURL (URL) downloads the given URL and returns the downloaded HTML. CURL () is often used to signal external applications of dial plan events. If our approach dictates making synchronous calls, then Asterisk will keep waiting until the called web page returns a reply. Just then, Asterisk can decide what to do. In case asynchronous calls are being made, Asterisk can continue without waiting for the http reply. However, it will not be able to take action because the reply might be received after the call is terminated.

- A web page will receive a request from Asterisk. This page might either consult the RBE immediately or connect to a Web Service that will do the job. Both options are valid, but we will use a Web Service to make sure our approach will work even when the RBE is running on a remote server, other than our web server. The web page can call the web service in synchronous or asynchronous mode.

- When it receives the request to make the current phone call, the RBE will check the rules and the CDR database. The rules will be stored in an XML file. The CDRs should be stored in an accessible database. By default, CDRs are stored in a text file, but Asterisk can be configured to 
store them in a MySQL database. Then, the RBE will use the ODBC driver of MySQL to connect to the database. Another alternative is to store the CDRs in SQL Server 2000 database.

- After the RBE checks the rules, it sets a string of actions to be taken. This string is returned in the form of an HTTP reply to Asterisk.

- Asterisk will receive the reply and decide what to do.

"Fig. 1" shows the flow of events along with the used protocols.

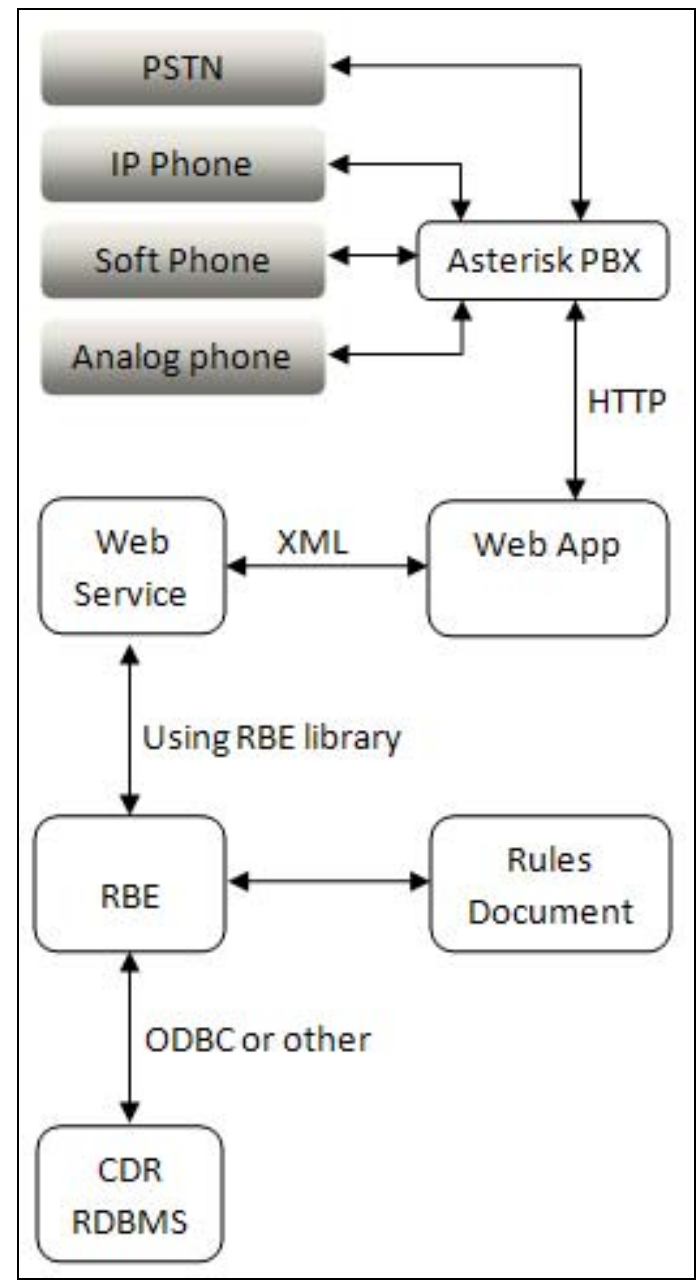

Fig. 1 - Flow of control

\section{RULES AND ACTIONS}

\section{A. RBE Rules}

This article does not focus on the rules themselves. It focuses on the way the integration is implemented. Rules will be developed at the discretion of the business owners. The need for better security and higher control play a crucial role in creating more rules. The development of rules is an ongoing process. Therefore, the number of rules is definitely expected to increase with time. RBE is instructed to take appropriate actions with the following scenarios:

\section{Personal Calls}

1.1 the same employee regularly calls the same number within the same time range

1.2 an outsider regularly calls within the same time range

1.3 a missed call occurs

\section{Busy Numbers}

2.1 an outsider keeps our fax number busy after business hours (Denial-of-Service attack)

2.2 all of our lines are busy

\section{Salesmen Performance}

3.1 an employee makes $25 \%$ more calls than what he/she had made during the previous month

3.2 an employee reaches $\mathrm{x}$ calls / week

3.3 an employee calls a client $25 \%$ above his / her average number of calls per month

\section{Client Problem}

4.1 a client calls but no one answers

4.2 a client makes $25 \%$ above his /her average calls per month

4.3 the duration of a client's call exceeds $\mathrm{x}$ minutes

\section{Monitored Numbers}

5.1 a specific client is called

5.2 a specific employee is called

5.3 two employees of different branches call each other

5.4 extension $\mathrm{x}$ is calling extension $\mathrm{y}$

\section{Local Calls}

6.1 the total duration of all local phone calls made today exceeds $\mathrm{x}$ minutes

6.2 the total duration of all local phone calls made this week exceeds $\mathrm{x}$ minutes

\section{Mobile Calls}

7.1 number of calls made to a mobile phone by the same employee exceeds $\mathrm{x} /$ week

7.2 an employee calls a client's mobile phone when the client can be reached through land lines

7.3 the total duration of all calls made to mobile phones exceeds $\mathrm{x}$ minutes

\section{Distance Calls}

8.1 an employee makes international calls more than $\mathrm{x}$ times / week 
8.2 the total duration of all international calls made this week exceeds $\mathrm{x}$ minutes

\section{Off Hours}

9.1 someone calls after business hours

9.2 someone calls during the weekend

\section{Miscellaneous}

10.1 the caller is the CEO

10.2 an employee is the most frequent caller

10.3 an employee is the most frequent callee

It is worth mentioning that there are other rules that can still be developed based on the need of business owners. Our goal is to allow the business owners to detect fraudulous activity. Basically, there are two pre-requisites to fraudulous activity detection. The first is to collect historical data about line activity. The second is to apply some statistical techniques on the data in order to build a model that tells which activity is fraudulous and which is not [5]. Data warehousing and data mining techniques can be also used to analyze the call records. Extreme care should be taken when using such CPU consuming techniques.

\section{B. Asterisk Actions}

For performance considerations, we can instruct the web server, rather than Asterisk, to perform certain actions that do not need Asterisk's intervention. Our approach is to let Asterisk perform all actions. Table 1 lists some of the actions that can be returned by the RBE.

TABLE 1 - ACTIONS AND THEIR MEANINGS

\begin{tabular}{|c|c|c|}
\hline Code & Meaning & Comments \\
\hline $\mathrm{AC}$ & $\begin{array}{l}\text { allow } \\
\text { call }\end{array}$ & $\begin{array}{l}\text { Everything is OK. No action is to be } \\
\text { taken }\end{array}$ \\
\hline $\mathrm{RC}$ & $\begin{array}{l}\text { reject } \\
\text { call }\end{array}$ & Something is wrong. Reject the call. \\
\hline NM & $\begin{array}{l}\text { non- } \\
\text { critical } \\
\text { mail }\end{array}$ & $\begin{array}{l}\text { Send an email to the system } \\
\text { administrator about this call. }\end{array}$ \\
\hline $\mathrm{CM}$ & $\begin{array}{l}\text { critical } \\
\text { mail }\end{array}$ & $\begin{array}{l}\text { Same as above. The email will be } \\
\text { flagged as critical. }\end{array}$ \\
\hline $\mathrm{CA}$ & $\begin{array}{l}\text { call } \\
\text { admin }\end{array}$ & $\begin{array}{l}\text { Call administrator and tell about the } \\
\text { call. }\end{array}$ \\
\hline RK & $\begin{array}{l}\text { record } \\
\text { and keep }\end{array}$ & $\begin{array}{l}\text { Record the call and keep it until the } \\
\text { administrator checks it. }\end{array}$ \\
\hline $\mathrm{RP}$ & $\begin{array}{l}\text { record } \\
\text { and play }\end{array}$ & $\begin{array}{l}\text { Record the call. When done, call the } \\
\text { administrator and play it to him / her. }\end{array}$ \\
\hline $\mathrm{BC}$ & $\begin{array}{l}\text { blacklist } \\
\text { the caller }\end{array}$ & $\begin{array}{l}\text { Do not accept any more calls from } \\
\text { the caller. The caller ID will be } \\
\text { stored in the RBE black list } \\
\text { document. }\end{array}$ \\
\hline $\mathrm{NO}$ & No CDR & Disable CDRs for the current call. \\
\hline
\end{tabular}

\section{PRODUCTS CONFIGURATION}

\section{Asterisk}

1) Dial Plan: When the call is about to be made, the dial plan should make a request to a web application. The called web page will return a string that includes a series of actions to be taken. Asterisk will take all of those actions. The following is a sample code to do so.

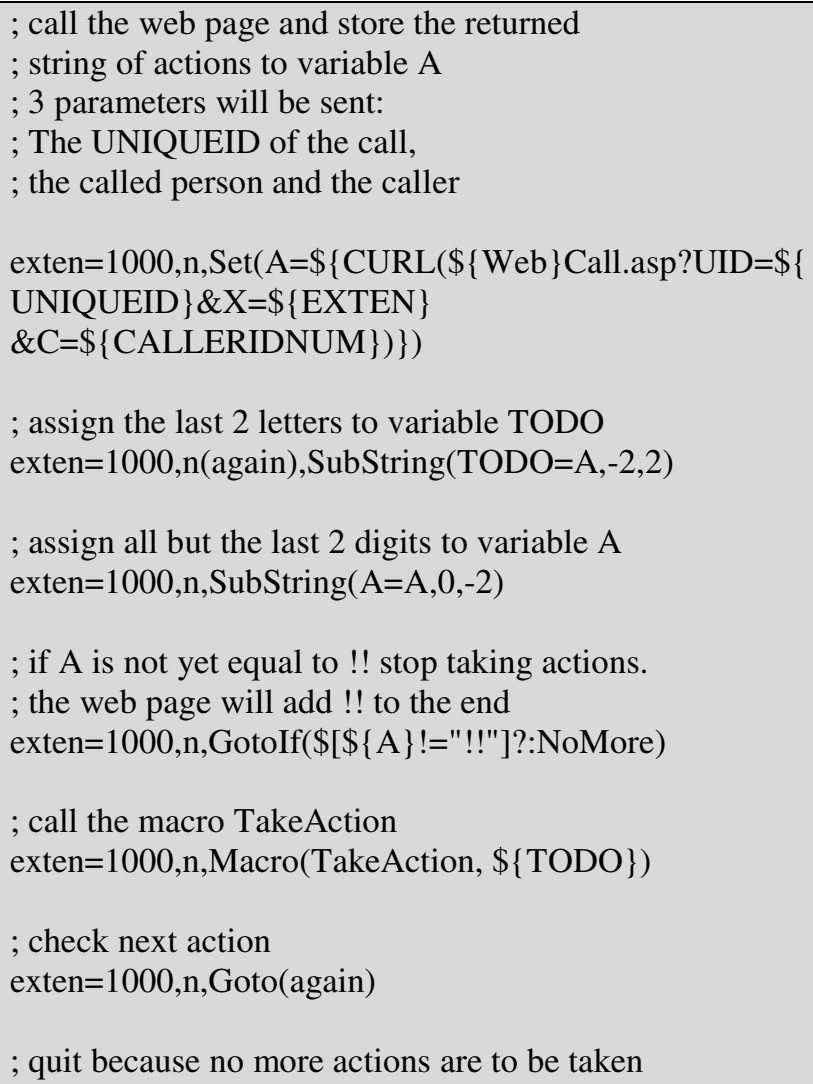

The "TakeAction" macro used above is simple and straightforward. It will receive a string of actions and take them one after the other.

2) $C D R$ Configuration: CDR filtering starts with identifying the CDR data fields [4]. Asterisk CDR table has 16 columns. In this article, we focus on 2 of them: source and destination. All what RBE requires is identifying the caller and the receiver. Asterisk uses the /var/log/asterisk/cdr-csv directory to store the CDRs. By default, this comma-separated text file is called Master.csv file. We are not interested in this file since the RBE needs to read data records from a database. Although the RBE can use ODBC (Open Database Connectivity) to connect to a text file and deal with it the same way it deals with a database, it is not a 
recommended approach. The performance is critical. Thus, the data should be indexed and optimized for retrieval. Those capabilities are found in any RDBMS (Relational Database Management System). Therefore, there is a need to store the CDRs in a database. At this stage, there are a plenty of options. InRule can connect to any database using the ODBC connectivity. Asterisk can be instructed to follow one of the following approaches:

- To store the CDRs in MS SQL Server through the use of unixODBC. This is recommended because InRule can easily connect to MS SQL Server.

- To store the CDRs in any Asterisk-supported database including SQLite, PostGreSQL, MySQL, and others. If this is the case, then the RBE will use ODBC connectivity to connect to the CDRs database.

Both approaches are valid, but we will follow the first one because when a call takes place, Asterisk will have enough time to store the CDR of the call in a database using ODBC connectivity. Then, the RBE will work with MS SQL Server and perform the required queries faster than connecting to another RDBMS using ODBC connectivity. This might not be the case if other RBEs are in use. For a detailed implementation regarding setting up Asterisk to work with ODBC, please refer to [2].

\section{Web Application}

The mission of the web application is easy. The main page will

i) receive a request from Asterisk

ii) send the request to the web service

iii) receive a reply as a list of actions to be taken

iv) send the action string back to Asterisk

The following is the Page_Load code of the only page:

CallMonitor.Service CM = new CallMonitor.Service();

string UniqID = Request.QueryString["UID"].ToString(); string Caller = Request.QueryString["C"].ToString();

string Called = Request.QueryString["X"].ToString(); string Actions $=$ CM.GetActions $($ UniqID, Caller, Called $)$;

Response.Write(Actions);

In order to be able to call the web service from the web page, there is a need to add a web reference to it. The web page should return only one string, which includes 2 letters for each action to be taken. In order to make sure that the web page will not return extra text such as $<$ html $>$ and $</$ html $>$, all text from the aspx page should be erased except for the following line of code:

$<\%$ @ Page Language="C\#" AutoEventWireup="true" CodeFile="Default.aspx.cs" Inherits="_Default" \%>

\section{E. Web Service}

The web service is closely related to the RBE. It does the following:

i) take 3 input parameters

ii) send them to the RBE

iii) instruct the RBE to do the required checking

iv) get feedback from RBE

v) send the reply back to the calling web page

Again, there is a need to add a reference to the RBE in order to be able to communicate with it. The following is our WebMethod:

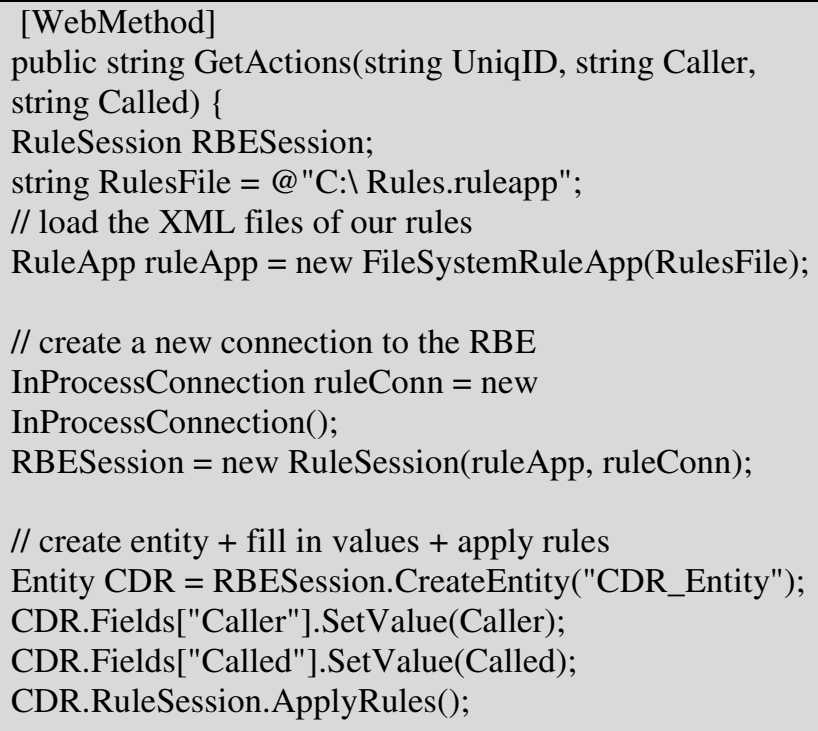

\section{F. $R B E$}

Although we decided to use InRule, any other RBE can do the job. We aim at assigning the decision making to an external tool. InRule can be easily replaced by many open-source or proprietary rule-based engines. Like other RBEs, InRule has graphical tools that allow the user to add, amend, delete, test, and verify the rules. If the user is a programmer or a database developer, he/she can create rules by writing code. The user can also write rules using natural business language. 
We will implement the rule 3.1 which states that when an employee makes $25 \%$ more calls than what he/she had made during the previous month, send a critical mail. To create this rule, we will use the irAuthor, a tool that comes with InRule and helps in creating and maintaining rules. First, we need to create an entity called CDR_Entity. Next, we create 3 fields that belong to it. Those fields are as follows:

TABLE 2 - RBE ENTITY FIELDS

\begin{tabular}{|l|l|l|l|}
\hline \multicolumn{1}{|c|}{ Name } & \multicolumn{1}{|c|}{$\begin{array}{c}\text { Data } \\
\text { Type }\end{array}$} & \multicolumn{1}{c|}{ I/O } & \multicolumn{1}{|c|}{ Comment } \\
\hline Caller & Text & I & $\begin{array}{l}\text { The phone number of the } \\
\text { caller }\end{array}$ \\
\hline Called & Text & I & $\begin{array}{l}\text { The phone number of the } \\
\text { receiver }\end{array}$ \\
\hline Actions & Text & O & $\begin{array}{l}\text { A string of characters. } \\
\text { Each 2 letters will let } \\
\text { Asterisk take a specific } \\
\text { action }\end{array}$ \\
\hline
\end{tabular}

After we have created the entity, we create our rule. "Fig. 2" shows the irAuthor tool where the entity is created and our rule appears as an if-then-else node:

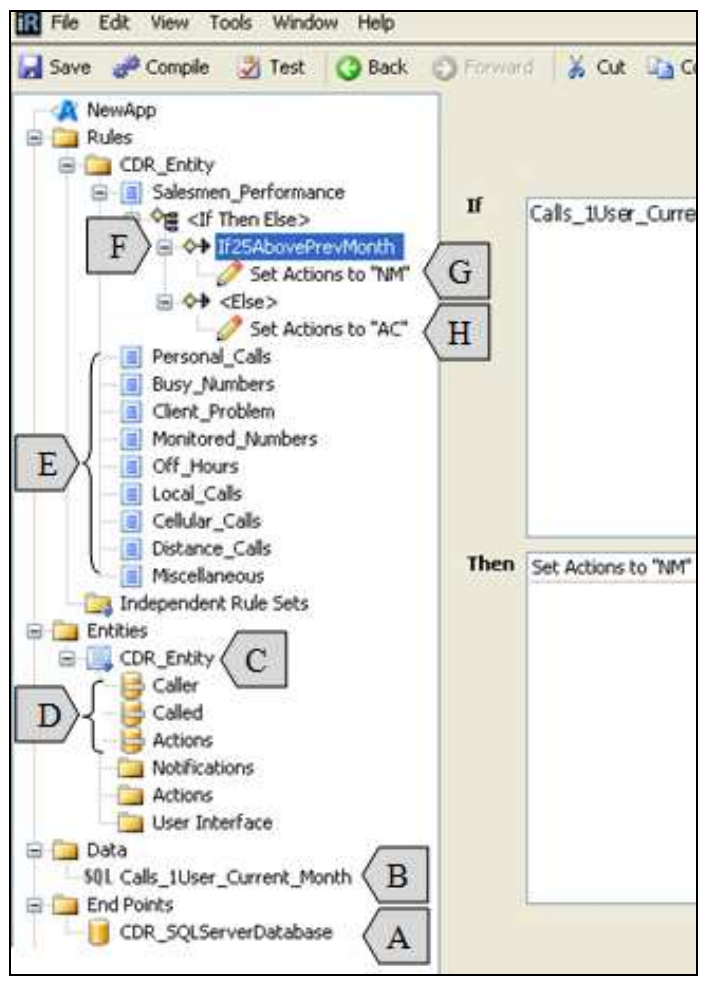

Fig. 2 - InRule Interface
TABLE 3 - IRAUTHOR LEGEND

\begin{tabular}{|c|c|}
\hline Mark & Description \\
\hline A & $\begin{array}{l}\text { This is the connection to the CDR database. As } \\
\text { long as the DBMS has an ODBC driver, } \\
\text { connectivity can be successfully achieved. }\end{array}$ \\
\hline B & $\begin{array}{l}\text { This is a query that accepts } 2 \text { parameters and } \\
\text { returns the number of phone calls made by a } \\
\text { certain user in the current month. The query is } \\
\text { as follows: } \\
\text { Select count }(*) \text { From CDRTable Where clid = } \\
\text { @ caller and month(calldate) }=\text { @ curmonth. } \\
\text { This query will be used in the if-then-else rule. }\end{array}$ \\
\hline $\mathrm{C}$ & This is our entity. It has 3 fields. \\
\hline $\mathrm{D}$ & $\begin{array}{l}\text { The first two fields of our entity are supplied by } \\
\text { the web service. The third is the output } \\
\text { parameter, the value of which will be decided } \\
\text { by the RBE and returned to the web service. } \\
\text { Thus, the web service tells the RBE who is } \\
\text { calling whom and the RBE tells the web service } \\
\text { what to do. }\end{array}$ \\
\hline $\mathrm{E}$ & $\begin{array}{l}\text { Those are sets of rules. We decided to create a } \\
\text { set for every category. }\end{array}$ \\
\hline $\mathrm{F}$ & $\begin{array}{l}\text { This is our rule. It is an if-then-else statement. } \\
\text { The formula that uses the query explained in B } \\
\text { is as follows: } \\
\text { Calls_1User_Current_Month(CDR_Entity.Calle } \\
\text { r; } \\
\text { (Calls_1User_Current_Month(C) } \\
\text { er; Month() - } 1 \text { ) } * 1.25 \text { ) } \\
\text { The left-hand side returns the number of calls } \\
\text { made by the caller (first field in our entity) in } \\
\text { the current month. The right-hand side returns } \\
\text { the number of calls made by the caller in the } \\
\text { previous month * } 1.25 \text {. When this condition is } \\
\text { met, it means that the user made } 25 \% \text { more calls } \\
\text { than the previous month. For simplicity sake, } \\
\text { this formula ignores the first month of the year. }\end{array}$ \\
\hline $\mathrm{G}$ & $\begin{array}{l}\text { This statement will be executed if the above } \\
\text { condition is satisfied. It will let the value of the } \\
\text { third field (Actions) equal to 'NM' which means } \\
\text { Non-critical Mail. Actions field will be returned } \\
\text { to the web service. The web service can send } \\
\text { the mail by itself or it can send the Actions } \\
\text { string back to Asterisk which in turn will send } \\
\text { the mail message. }\end{array}$ \\
\hline $\mathrm{F}$ & $\begin{array}{l}\text { This statement will be executed if the above } \\
\text { condition is not satisfied. It will let the value of } \\
\text { the third field (Actions) equal to 'AC' which } \\
\text { means Allow the Call. }\end{array}$ \\
\hline
\end{tabular}

A number of arrows are placed in "Fig. 2". Table 3 explains those marks: 


\section{RESULTS}

We have developed a simple dial plan that keeps generating phone calls to test the performance of the servers. The goal is to measure the CPU load of each server. All servers have similar hardware. The processor is $2.4 \mathrm{GHz}$ Pentium IV and the capacity of the RAM is 2 GB. Echo cancellation is turned off because it doubles the CPU consumption. Table 4 shows the configuration of the servers:

TABLE 4 - SERVERS COMPONENTS

\begin{tabular}{|l|l|}
\hline Server & Installed Components \\
\hline Asterisk & AsteriskNOW 1.0.2.1 \\
\hline Web App. & Win. Server 2003 + IIS \\
\hline RBE & Win. Server 2003 + InRule \\
\hline $\begin{array}{l}\text { CDR } \\
\text { Database }\end{array}$ & $\begin{array}{l}\text { Win. Server 2003 } \\
+ \text { SQL Server 2000 }\end{array}$ \\
\hline
\end{tabular}

Table 5 shows the CPU load of our four servers per the number of active channels. In this table, each server has a column specifying the percentage of the CPU usage for the corresponding number of active channels.

TABLE 5 - CPU USAGE / ACTIVE CHANNELS

\begin{tabular}{|l|l|l|l|l|}
\cline { 2 - 5 } \multicolumn{1}{c|}{} & \multicolumn{4}{c|}{ Percentage of Server CPU Usage } \\
\hline $\begin{array}{c}\text { Concurrent } \\
\text { Calls }\end{array}$ & Asterisk & Web App & RBE & SQL Server \\
\hline 10 & 5 & 2 & 8 & 11 \\
\hline 20 & 10 & 8 & 17 & 20 \\
\hline 30 & 15 & 10 & 26 & 33 \\
\hline 50 & 25 & 15 & 45 & 52 \\
\hline 100 & 50 & 35 & 87 & 95 \\
\hline
\end{tabular}

"Fig. 3" shows the CPU measurements.

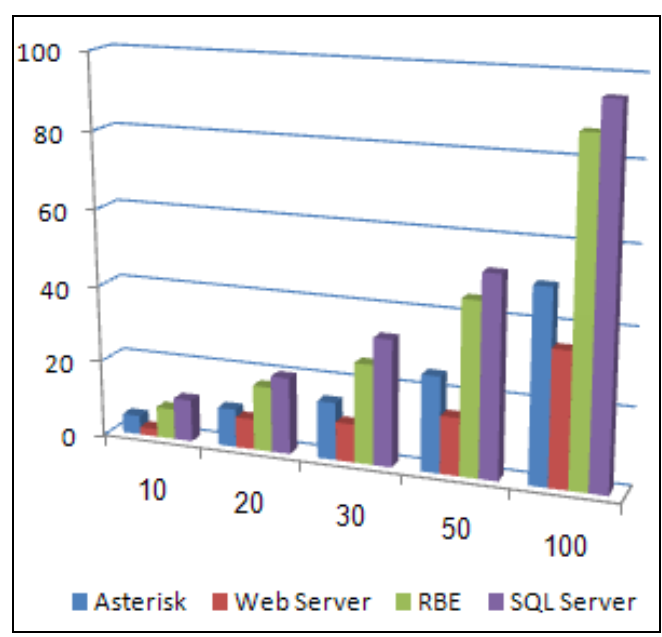

Fig. 3 - CPU Measurements
It is clear that this system can handle up to 80 concurrent calls without a problem. The main factor that still affects the above measurements is the number of rules defined in the RBE. This is true because the RBE will check the call request against all defined rules. Another crucial factor is the logic of the rules. Needless to say, a data-mining rule might bring the server to its knees. All of our tests were made using only 30 uncomplicated rules.

Response time is affected by many factors. We could achieve real time response when the server was handling less than 25 concurrent calls. Above this threshold, it was so clear that the server is becoming slower. In fact, our tests showed that when the server held 50 concurrent calls, we got a latency of 3 seconds. Such latency is not acceptable and will disturb the two communicating parties. We believe that load balancing can do a lot in this regard.

\section{LIMITATIONS}

The RBE-oriented approach has certain limitations that might make it less likely to be followed. Those limitations are the following:

- Four servers are used (Asterisk + Web App Server + Web Service Server + RBE Server + CDR Database Server). This implies that the whole setup will stop functioning if any of the servers goes down. Our objective in the near future is to reduce this number.

- The architecture is complex and difficult to maintain. Experts in several technologies (VoIP, Web, Database, and RBE) are required to keep the servers running.

- The CPU load tests do not seem to be satisfactory although they are encouraging.

\section{CONCLUSION}

In this article, we described the integration of Asterisk and InRule. The goal is to allow our PBX to trigger some actions when specific events take place. We could have omitted the use of RBE by simply creating a tool that analyzes the CDRs, and reports suspicious calls to the user. This would mean that an incident - such as a client making an excessive number of phone calls - will occur but no notifications would be made unless someone would specifically ask for a report. What we could achieve in this article is a real time response. Moreover, the use of RBE will allow business owners and nontechnical users to express their needs in form of rules since rule-based engines are made for this purpose.

Whenever a phone call is about to be made, Asterisk will make an http request to a web page that will call a 
web service, which in turn will call InRule. Although the web service or the web application could have been designed to take some actions, we decided that Asterisk is the best "action taker" because some actions include recording or blocking the phone call. Our approach allows the use of both: synchronous and asynchronous call to the web service. If the synchronous approach slows down the performance of the PBX, it is advisable to follow the asynchronous one.

\section{FUTURE WORK}

To ensure the effectiveness of the solution proposed in this article, more tests and measurements need to be considered. The main two factors which need to be more emphasized are the number and the complexity of the rules. Real-life scenarios, rules, actions, and phone calls will lead to more accurate benchmarking. The following factors will also affect the curve:

- types of used phones

- number of external lines

- employed codecs

- voicemail availability

- conferencing

- recording

- faxing
- $\quad$ voice menu

- text-to-speech translation

- speech recognition

- load balancing

- encryption

- firewall configuration

\section{REFERENCES}

[1] C. W. Ong and Tay Joc Cing, "A Robust Rule-based Event Management Architecture for Call-Data Records," accepted for publication in the Eighth International Conference on KnowledgeBased Intelligent Information and Engineering Systems 2004.

[2] J.Van Meggelen, L.Madsen \& J.Smith, Asterisk ${ }^{\mathrm{TM}}$ The Future of Telephony, 2nd Edition, O’Reilly Media Inc, 2007. Retrieved October 10, 2009, from http://astbook.asteriskdocs.org/en/2nd_Edition/asterisk-book-htmlchunk/asterisk-CHP-12.html.

[3] M. Spencer, M. Allison, and C. Rhodes, The Asterisk Handbook. Asterisk Documentation Team, 2003.

[4] Nikbakht, E. and Tafti, M.H.A, Application of Expert Systems in evaluation of credit card borrowers. Managerial Finance 15/5, 1927, 1989.

[5] Peter B., John S., Yves M., Bart P., Christof S., Chris C., Fraud Detection and Management in Mobile Telecommunications Networks, Proceedings of the European Conference on Security and Detection ECOS 97, pp. 91-96, London, April 28-30, 1997. ESAT-SISTA TR97-41. 